\title{
PEDAGOGIA QUEER: UMA NOVA PROPOSTA NO MEIO EDUCACIONAL
}

\author{
Marcus Alexandre de Pádua Cavalcanti ${ }^{1}$ \\ Sandramor do Amaral Ferreira ${ }^{2}$
}

\begin{abstract}
RESUMO
A apropriação da Teoria Queer por teóricos da educação surgiu do esforço de estudiosos da área de ensino em utilizar conceitos produzidos para pensar novas estratégias pedagógicas não normativas. A Teoria Queer possibilita a construção de novas pedagogias que não investem em uma perspectiva binária de gênero e de sexualidade. Pela importância de suas contribuições no campo da Educação, a Teoria queer pode ser uma importante interlocutora em uma contemporaneidade na qual as concepções sobre o sujeito pedagógico e sobre os métodos de ensino-aprendizagem parecem estar em crise arrastados pelo surgimento de diferentes formas de gênero e de sexualidade que surgem no espaço escolar. Desse modo, o presente trabalho tem como objetivo compreender o que esta teoria tem a dizer para o campo da Educação.

Palavras-chave: pedagogia queer; sexualidade; gênero; currículo; diversidade sexual
\end{abstract}

\section{PEDAGOGY QUEER: A NEW PROPOSAL IN THE EDUCATIONAL ENVIRONMENT}

\begin{abstract}
The appropriation of Queer Theory by education theorists arose from the effort of scholars in the area of teaching to use concepts produced to think new non-normative pedagogical strategies. What seems to be common to all theorists who use queer theory seems to be the possibility of constructing new pedagogies that allow for less gender-normalizing discourses and sexuality. Due to the importance of its contributions in the field of Education, Queer Theory can be an important interlocutor in a contemporaneity in which our conceptions about the pedagogical subject and our teaching-learning methods seem to be in crisis dragged by the emergence of new ways of thinking questions Gender and sexuality that inhabit the school space. Thus, the present work aims to understand what this theory has to say for the field of Education.
\end{abstract}

Keywords: queer pedagogy; sexuality; genre; curriculum; Sexual diversity

\footnotetext{
${ }^{1}$ Doutorando em Educação em Ciências e Saúde - Universidade Federal do Estado do Rio de Janeiro - UFRJ Membro do Laboratório de Linguagens e Mediações - UFRJ - Centro de Ciências da Saúde. E-mail: marcus_nathan1203@hotmail.com

${ }^{2}$ Bacharel e Pós Graduada em Designer de Moda- SENAI CETIQT - Coordenadora da área de Moda do Serviço Nacional de Aprendizagem Comercial do Rio de Janeiro (SENAC). E-mail: sandramoramaral@ gmail.com
} 


\section{INTRODUÇÃO}

De acordo com Foucault (1987), desde algumas décadas, estamos sendo atravessados por saberes que tem como objetivo produzir indivíduos assujeitados. $\mathrm{O}$ autor afirma que aprendemos que as práticas discursivas são instituidoras dos objetos dos quais falam, moldam nossas formas de constituir o mundo, o que trouxe novos desafios às pesquisas na área de educação, desnaturalizando ainda mais a possibilidade de uma observação passiva, descritiva e objetiva do objeto dessas áreas do conhecimento. Portanto, quando nos debruçamos mesmo sobre conceitos como sexualidade e gênero que se tornaram também um objeto de discurso das pesquisas educacionais, é preciso lembrar que esses discursos produzem as próprias identidades sexuais e de gênero sobre as quais se debruçam em uma complexa trama de saberes e poderes, cuja análise sempre é necessária quando se parte de uma pesquisa com foco nos estudos da Educação Queer, já que o currículo não é mais apenas um instrumento de transmissão de conhecimento, nem espaço de significação, mas é também um espaço de produção de identidades. A teoria Queer permite pensar a ambiguidade, a multiplicidade e a fluidez das identidades sexuais e de gênero, mas, além disso, também sugere novas formas de pensar a cultura, o conhecimento, o poder e a educação. (LOURO, 2004, p.550)

Mesmo com o surgimento de grupos LGBTT (Lésbicas, Gays, Bissexuais, Travestis e Transexuais), as posições de sujeito permanecem com restrições em relação aos seus contornos e limites. Assim, também essas identidades sexuais passaram a ser questionadas por não abarcarem toda a complexidade e pluralidade das possíveis formas de manifestação da sexualidade. Com isso há uma mudança nos movimentos sexuais e de gênero que atingem o campo da educação e que igualmente exigem uma transformação nas teorias que deles se ocupavam. É dentro desse quadro que a teoria queer precisa ser compreendida.

O referencial teórico deste trabalho está fundamentado na perspectiva pósestruturalista. Buscaremos as contribuições na obra de Michel Foucault (1987, 1988, 1992, $1995)$ - especialmente as noções de modos de subjetivação e no dispositivo da sexualidade -, da teórica queer Judith Butler (2003) e dos teóricos da educação Guacira Louro (1997, 2003) e Silva (2004), que tem sido no Brasil os principais articuladores desses esforços em pensar as contribuições da Teoria Queer na área da educação. 
Desse modo, o presente trabalho tem como objetivo compreender o que esta teoria tem a dizer para o campo da Educação. O primeiro momento do artigo busca explicitar as contribuições da Teoria Queer na área da educação. No segundo, o objetivo é refletir acerca das questões de Gênero e Sexualidade também no campo educacional. No terceiro momento apontamos a crítica da teoria Queer aos modelos binários e aos ditames heteronormativos.

\section{A PEDAGOGIA QUEER}

A Pedagogia Queer nasce do esforço teórico de pesquisadoras da área da Educação em utilizar conceitos produzidos pela Teoria Queer para pensar novas estratégias pedagógicas que não sejam normativas. A pesquisadora Guacira Lopes Louro tem sido no Brasil a principal articuladora para pensar as contribuições da Teoria Queer na área da educação. Ela também circunscreve algumas das principais inquietações no desenvolvimento de uma Pedagogia Queer

Como um movimento que se remete ao estranho e ao excêntrico pode articular-se com a Educação, tradicionalmente o espaço da normalização e do ajustamento? Como uma teoria não-propositiva pode "falar" a um campo que vive de projetos e de programas, de intenções, objetivos e planos de ação? Qual o espaço nesse campo usualmente voltado ao disciplinamento e à regra, para a transgressão e para a contestação? Como romper com binarismos e pensar a sexualidade, os gêneros e os corpos de uma forma plural, múltipla e cambiante? Como traduzir a teoria queer para a prática pedagógica? (LOURO, 2004, p. 47).

A Teoria Queer aparece no fim dos anos 1980 nos Estados Unidos. O termo queer foi empregado pela primeira vez em 1990, em uma conferência nos Estados Unidos. Com inspiração desta provocação, como também na teoria feminista, na psicanálise, e principalmente nas teorias francesas pós-estruturalistas, pesquisadores que estudavam os conceitos de sexualidade e gênero encontraram instrumentos para pensar um novo campo de estudos que pudesse ser uma alternativa aos referenciais identitários presentes na teoria feminista e dos estudos LGBTT nas universidades americanas. (LOURO, 2004). 
Butler (2001) afirma a expressão queer tem sido usado na literatura anglo-saxônica, para englobar os termos "gay" e "lésbica". A autora explicita que a teoria queer é uma teoria sobre gênero que afirma que a orientação sexual e a identidade sexual ou de gênero dos indivíduos são o resultado de um constructo social e que, portanto, não existem papéis sexuais essencializados ou biologicamente inscritos na natureza humana, mas antes, formas socialmente variáveis de desempenhar um ou vários papéis sexuais.

Historicamente, o termo queer tem sido empregado para se referir, de forma depreciativa, as pessoas que não são heterossexuais. Sua utilização pelos ativistas dos movimentos LGBTT constitui uma tentativa de recuperação da palavra, revertendo sua conotação negativa original. Essa utilização renovada da palavra queer joga também com um de seus outros significados, o de "estranho".

De acordo com Miskolci (2009, p. 170)

A Teoria Queer desafia a Sociologia a não mais estudar apenas os que rompem as normas (o que redundaria nos limitados estudos de minorias), nem apenas os processos sociais que os criam como desviantes (o que a teoria da rotulação já fez com sucesso), antes focar nos processos normalizadores marcados pela produção simultânea do hegemônico e do subalterno.

Nesse sentido, Louro (2004) afirma que a educação heteronormativa - defendida pelos setores conservadores contra a inclusão do gênero e sexualidade nos currículos - possui sua ideologia: gênero como algo mistificado e inquestionável que busca camuflar a diversidade em prol do binarismo fundante da heterossexualidade compulsória. Esses setores ocultam sua ideologia de gênero através da expressão "ideologia de gênero" que desqualifica outras ideias mais próximas ao reconhecimento da diversidade e do caráter performativo dos gêneros inteligíveis.

Um dos alvos da teoria queer é a própria idéia de heteronormatividade, conceito criado pelo pesquisador americano Michael Warner (1993) para descrever a norma que toma a sexualidade heterossexual como padrão universal e os discursos que descrevem a situação homossexual como desviante.

Segundo Butler (2000) a teoria queer afirma que a orientação sexual e a identidade sexual ou de gênero dos indivíduos são o resultado de um processo de construção social e que, portanto, não existem papéis sexuais essenciais ou biologicamente inscritos na natureza 
humana, antes, formas socialmente variáveis de desempenhar um ou múltiplos papéis sociais. Assim, os teóricos queer promovem a quebra com o pensamento clássico de gênero que prega a existência de sexualidades "normais", por isso aceitas (heterossexualidade) e "anormais", por isso recusadas (homossexualidade).

Butler (2000) afirma que as sociedades constroem normas que regulam e materializam o sexo dos sujeitos e que essas normas regulatórias precisam ser constantemente repetidas e reiteradas para que tal materialização se concretize. Entretanto, ela acentua que "os corpos não se conformam, nunca, completamente, às normas pelas quais sua materialização é imposta" (BUTLER, 2000, p. 154). Sendo assim, as normas regulatórias do sexo têm caráter performativo, ou seja, "a linguagem que se refere aos corpos ou ao sexo não faz apenas uma constatação ou uma descrição desses corpos, mas, no instante mesmo da nomeação, constrói, faz aquilo que nomeia, produz os corpos e os sujeitos" (LOURO, 2001, p.548).

\section{GÊNERO E SEXUALIDADE NA EDUCAÇÃO}

Os estudos sobre a sexualidade realizados pelo filósofo francês Michel Foucault também foram uma forte inspiração para os autores da teoria queer. Para Foucault (1988), a sexualidade é um dispositivo da modernidade constituído por práticas discursivas e não discursivas que produzem uma concepção do indivíduo enquanto sujeito de uma sexualidade, ou seja, saberes e poderes que buscam normatizar, controlar e estabelecer verdades acerca do sujeito na relação com seu corpo e seus prazeres. Observa-se aqui a superação da tematização da sexualidade enquanto objeto natural e sua construção enquanto dispositivo de poder. Foucault (1988) observa ainda que mecanismos específicos de conhecimento e poder centrados no sexo se conjugam, desde o século XVIII, através de uma variedade de práticas sociais e técnicas de poder.

Portanto, discursos sobre a sexualidade das mulheres e das crianças, sobre o controle do comportamento procriativo e sobre a demarcação das perversões sexuais, produziram, ao longo do século XIX, quatro figuras submetidas à observação e ao controle social: a mulher histérica, a criança masturbadora, o casal malthusiano e o pervertido, especialmente o homossexual. Foucault conclui que é no século XIX que se produz o conceito de homossexualidade: "foi por volta de 1870, que os psiquiatras começaram a constituí-la com 
objeto de análise médica: ponto de partida, certamente, de toda uma série de intervenções e de controles novos" (FOUCAULT, 1992, p. 233).

Mas a grande inquietação de Foucault (1988) em relação ao discurso sobre a homossexualidade está na cristalização de uma pseudo-identidade que poderia obstruir a produção de novas estéticas da existência, ou seja, novas formas de ser e estar no mundo. Neste sentido a preocupação de Foucault está em consonância com a crítica da Teoria Queer às limitações identitárias dos Estudos Gays e Lésbicos. Para Foucault a questão é saber quais relações podem ser estabelecidas, inventadas, multiplicadas, moduladas através da homossexualidade.

Para Foucault (1995, p. 239) a grande resistência política na modernidade talvez "não seja descobrir o que somos, mas recusar o que somos. Temos que promover novas formas de subjetividade, através da recusa deste tipo de individualidade que nos foi imposto há séculos".

Louro (1997) afirma que as contribuições de Foucault, ao desnaturalizar o conceito de sexualidade por entendê-la como um dispositivo produzido por redes de saber e poder possibilitaram também o fortalecimento das discussões sobre o conceito de gênero entre as teóricas feministas, embora especificadamente o conceito de gênero não tenha sido objeto das pesquisas foucaultianas. O conceito de gênero foi introduzido pelas feministas de língua inglesa na década de 1970, designando as representações acerca do masculino e do feminino que são construídas culturalmente, distanciando-se de uma compreensão biologizante. Para Louro (1997, p. 23), a importância do conceito de gênero

Obriga aquelas/es que o empregam a levar em consideração as distintas sociedades e os distintos momentos históricos de que estão tratando. Afastase (ou se tem a intenção de afastar) proposições essencialistas sobre os gêneros; a ótica está dirigida para um processo, para uma construção, e não para algo que exista a priori. O conceito passa a exigir que se pense de modo plural, acentuando que os projetos e as representações sobre mulheres e homens são diversos. Observa-se que as concepções de gênero diferem não apenas entre as sociedades ou os momentos históricos, mas no interior de uma dada sociedade, ao se considerar os diversos grupos (étnicos, religiosos, raciais, de classe) que a constituem.

Mas os instrumentos analíticos de Foucault possibilitaram também a algumas pesquisadoras da teoria queer, como a americana Judith Butler, a pensar o conceito de gênero ainda mais longe. Para Butler (2003) o gênero não exprime uma essência, uma disposição 
natural, mas é definido como o efeito repetitivo de uma performance. A coerência e a continuidade entre as categorias de sexo, gênero e sexualidade são culturalmente construídas na repetição de ações estilizadas. Essa repetição que produz a aparência ontológica binária e essencialista dessas categorias é o que a autora chama de performatividade. No caso específico da distinção binária entre sexo-gênero, ela serviria também para encobrir a multiplicidade de outras possibilidades que envolvem a construção de nossas identidades sexuais e de gênero.

Se o gênero é a construção social do sexo e se não existe nenhum acesso a esse 'sexo' exceto por meio de sua construção, então parece não apenas que o sexo é absorvido pelo gênero, mas que o 'sexo' torna-se algo como uma ficção, talvez uma fantasia, retroativamente instalado em lugar pré-lingüistico ao qual não existe nenhum acesso direto (BUTLER, 2000, p. 158).

Ainda para Butler (2000, p. 153) "a diferença sexual não é, nunca, simplesmente, uma função de diferenças materiais que não seja, de alguma forma, simultaneamente marcadas e formadas por práticas discursivas".

\section{A CRÍTICA DA TEORIA QUEER AOS MODELOS BINÁRIOS}

A Teoria Queer rompe com os binarismos sexo-natureza/gênero-cultura, ao sugerir que o sexo é cultural, na mesma medida em que o é o gênero. Consequentemente, a própria distinção sexo/gênero fica perturbada. O gênero é o meio discursivo/cultural mediante o qual um 'sexo natural' é estabelecido como pré-discursivo. Em outras palavras, "o sexo é, ele próprio, uma postulação, um constructo que se faz no interior da linguagem e da cultura" (LOURO, 2004, p. 66-67).

É a partir dessa perspectiva que a pedagogia queer é pensada. Esta não propõe somente incluir no currículo informações sobre a sexualidade, mas questionar os processos institucionais e discursivos, as estruturas de significação que definem os papéis sociais e as identidades dos sujeitos que fazem parte do cotidiano escolar. Ela abre a possibilidade de discussão do que consideramos ser fixo, imutável. Não apenas em relação aos currículos 
escolares, mas nas relações que se imbricam nos cotidianos escolares, que nos possibilita perceber os outros diferentes de nós (SILVA, 2004).

As críticas da teoria queer aos modelos binários de gênero e sexualidade tem inspirado teóricos que fazem uso do termo a criticarem também os modelos da epistemologia moderna na área da educação. Para o pesquisador brasileiro Tomaz Tadeu da Silva (2004, p. 107).

O queer se torna assim uma atitude epistemológica que não se restringe à identidade e ao conhecimento sexuais, mas que se estende para o conhecimento e a identidade de modo geral. Pensar queer significa questionar, problematizar, contestar, todas as formas bemcomportadas de conhecimento e de identidade. A epistemologia queer é, nesse sentido, perversa, subversiva, impertinente, irreverente e profana.

Para Louro (2004) há também na pedagogia queer uma provocação e uma perturbação das formas convencionais de pensar e conhecer. Mas diferente de uma pedagogia do oprimido, ela escapa mesmo dos enquadramentos do dualismo presente nas teorias que trabalham com uma crítica da lógica da dominação. Ao invés de uma resposta apaziguadora se propõe um trabalho incessante de eterna busca

Vistos sob essa perspectiva, uma pedagogia queer fala a todos e não se dirige apenas àqueles ou àquelas que se reconhecem nessa posição-desujeito, isto é, como sujeitos queer. Uma tal pedagogia sugere o questionamento, a desnaturalização e a incerteza como estratégias férteis e criativas para pensar qualquer dimensão da existência. A dúvida deixa de ser desconfortável e nociva para se tornar estimulante e produtiva. As questões insolúveis não cessam as discussões, mas, em vez disso, sugerem a busca de outras perspectivas, incitam a formulação de outras perguntas, provocam o posicionamento a partir de outro lugar. Certamente, essas estratégias também acabam por contribuir com a produção de determinado "tipo" de sujeito. Mas, nesse caso, longe de pretender atingir, finalmente, um modelo ideal, esse sujeito - e essa pedagogia - assumem seu caráter intencionalmente inconcluso e incompleto (LOURO, 2004, p. 52).

Silva (2004) conclui que a partir da teoria queer todo o conhecimento legitimado como verdadeiro na educação, tradicionalmente concebida como um espaço onde se ensina a pensar, onde se transmite o pensamento, onde se aprende o raciocínio e a racionalidade, pode ser questionado, desfeito e construído de outra forma. Pensar sob a perspectiva queer 
significa questionar, problematizar, contestar, todas as formas tradicionais de conhecimento, inclusive as verdades cristalizadas na e pela escola.

\section{CONCLUSÃO}

A partir do exposto, concluímos que o que parece comum a todos os teóricos da pedagogia queer é justamente a aposta na possibilidade de se construir novas pedagogias que possibilitem que haja menos discursos normalizadores de gênero e sexualidade. Pela importância de suas contribuições no campo da Educação, a pedagogia queer pode ser uma importante interlocutora em uma contemporaneidade na qual nossas concepções sobre as múltiplas identidades, sobre o sujeito pedagógico e sobre nossos métodos de ensinoaprendizagem parecem estar em crise. Em um mundo no qual o sujeito pedagógico da educação tradicional era visto apenas do lugar das diferenças econômico-sociais, na contemporaneidade ele é percebido também por uma multiplicidade de novas identidades sexuais, de gênero e culturais que trazem novos problemas para os educadores que encontram dificuldades em utilizar as metodologias convencionais. Compreendemos que a utilização de uma pedagogia queer possibilita um certo apaziguamento diante do mal-estar que educadores sentem frente à volatilidade e à acelerada desterritorialização das identidades e das certezas que fabricamos ao longo da nossa história da educação, nos ensinando assim, a conviver melhor com contradições, incertezas, paradoxos e multiplicidades.

\section{REFERÊNCIAS}

BUTLER, Judith. Corpos que pesam: sobre os limites discursivos do "sexo". In: LOURO, Guacira Lopes (org.). O corpo educado: pedagogias da sexualidade. Belo horizonte: Autêntica, 2000.

BUTLER, J. Problemas de gênero: feminismo e subversão da identidade. Rio de Janeiro: Civilização Brasileira, 2003.

FOUCAULT, Michel. A arqueologia do saber. Rio de Janeiro: Forense Universitária, Volume, 1987.

História da sexualidade I: a vontade de saber. Rio de Janeiro: Graal, 1988. 
Microfísica do Poder. Rio de Janeiro: Graal, 1992.

O sujeito e o poder. IN: DREYFUS, Hubert; RABINOW, Paul. Michel Foucault, uma trajetória filosófica: para além do estruturalismo e da hermenêutica. Rio de Janeiro: Forense-Universitária, 1995. p. 231-249.

LOURO, Guacira Lopes. Gênero, sexualidade e educação: uma perspectiva pósestruturalista. Petrópolis: Vozes, 1997.

Um corpo estranho - ensaios sobre sexualidade e teoria queer. Belo Horizonte: Autêntica, 2004.

MISKOLCI, Richard. A Teoria Queer e a Sociologia: o desafio de uma analítica da normalização. Sociologias, Porto Alegre, n. 21, p. 150-182, jan./jul. 2009.

SILVA, Tomaz Tadeu. Documentos de identidade: uma introdução às teorias do currículo. Belo Horizonte: Autêntica, 2004.

WARNER, M. Fear of a queer planet: queer politics and social theory. Minneapolis: University of Minnesota Press, 1993. 